\title{
Oxytocin-functions: an overview
}

\begin{abstract}
Oxytocin is a neuropeptide containing nine amino acids produced by paraventricular and supraoptic nuclei of hypothalamus. Oxytocin is derived from a Greek word 'oxutokia' meaning sudden delivery and it is well known for its role in parturition and lactation. In addition oxytocin performs a wide spectrum of functions. Oxytocin is a hormone with great potential and it is a great facilitator of life. The purpose of this review is to cover almost all the functions of oxytocin - reproductive functions, social functions, role in human behaviour and other biologically significant functions..
\end{abstract}

Keywords: oxytocin, functions, neurophysin I, magnocellular neurons
Volume 6 Issue 4 - 2019

\author{
Roopasree B, Jophy Joseph, Mukkadan JK \\ Department of Physiology, Little Flower Institute of Medical \\ Sciences and Research, India
}

Correspondence: Mukkadan JK, Research Director, Department of Physiology, Little Flower Medical Research Centre LFMRC, Angamaly, Kerala, India, Tel 9I 93875I8037, Fax 0484 2452646,Email drmukkadan@gmail.com

Received: July 24, 2019 | Published: August 16, 2019

\section{Introduction}

Oxytocin is a non a-peptide hormone containing nine amino acids, with one disulphide linkage between the 1st and 6th cysteine residue. It is also called as $\alpha$-Hypophamine. Half-life is found to be minutes. It is known to be the 1 st polypeptide hormone that has been sequenced and synthesized biochemically. It is synthesized in the magnocellular neurosecretory cell bodies of both supraoptic and paraventricular hypothalamic nuclei and is stored in hypothalamo-hypophyseal tract until it is released into the blood. It is mainly secreted from the neurosecretory cells of paraventricular hypothalamic nucleus. ${ }^{1}$ Oxytocin is synthesized as a large molecule, the prohormone system called oxytocin - neurophysin I complex. The prohormone is then packaged in the Endoplasmic Reticulum and Golgi apparatus in a secretory granule that is membrane bounded in the cell bodies of both paraventricular and supraoptic nuclei. It is then transported intra axonally to the axon terminals located in posterior pituitary. ${ }^{2-4}$ Herring bodies at the axon terminals stores this complex until there the arrival of a stimulus. When a suitable stimulus reaches the posterior pituitary from hypothalamus, oxytocin is released into the blood. Oxytocin is secreted in both males and females. ${ }^{5}$

Before release of oxytocin, it is cleaved from neurophysin I. It occurs mainly by the action of enzyme peptidylglycine $\alpha-$ amidating monooxygenase. ${ }^{6}$ In addition to magnocellular neurons of hypothalamus, it is also present in the nerve endings which project on to brain stem, spinal cord and gonad. ${ }^{7}$ With the help of HPLC and radioimmunoassay, an oxytocin like peptide was detected in the testes of both humans and rats. Various studies provide demonstrative evidence to prove local synthesis of oxytocin within reproductive tract. In the case of female buffaloes and cows, oxytocin is also found to be synthesized from the corpus luteum. ${ }^{8}$ The production of this hormone from other local areas suggest its paracrine activity near the sites of production. ${ }^{9}$ As per the previous reports the other non-neural sites of oxytocin synthesis include, epididymis ${ }^{10,11}$ interstitial cells of Leydig, ${ }^{12}$ prostrate, ${ }^{13}$ adrenal medulla,,${ }^{14}$ placenta, ${ }^{15}$ retina, ${ }^{16}$ thymus,${ }^{17}$ pancreas ${ }^{18}$ etc. It is also known that oxytocin receptors are present in the reproductive tract of both sexes and they are accepted as key paracrine regulators in both males and females.

\section{Mechanism of action}

Currently, oxytocin is known to have only a single receptor. ${ }^{19}$ It is a member of the rhodopsin-type (class I) G-protein-coupled receptor
(GPCR) family. It is coupled to phospholipase C through Gaq11. ${ }^{20,21}$ Once Oxytocin binds to its receptor, it gives rise to a cascade of reactions that finally activates the enzyme Phospholipase-C. This enzyme produces ITP (inositol triphosphate) and DAG (1, 2-diacyl glycerol) and also activates intracellular $\mathrm{Ca}++$ release, which in turn set off various cellular events. ${ }^{9}$

The $\mathrm{Ca}++$ binding protein in myometrium called Calmodulin binds to $\mathrm{Ca}++$ in order generate $\mathrm{Ca}++-C a l m o d u l i n$ complex. This complex later on stimulates Myosin Light Chain Kinase (MLCK) enzyme to cause contraction of smooth muscles. The reason for this indirect action of Oxytocin is its stimulatory action on the synthesis of PGF $2 \alpha .{ }^{22}$ Because of its ability to induce contraction of myometrial smooth muscles, both the activation and the inhibition of oxytocin receptor have long been targeted in the management of dysfunctional and preterm labours respectively.

\section{Function of oxytocin}

Oxytocin is acknowledged as a female hormone. The term oxytocin is derived from Greek word meaning 'quick birth'. It performs a wide variety of functions. The pituitary gland secretions are responsible for the peripheral functions of the hormone. The secretions from centrally projecting Oxytocin neurons that differ from those that enter posterior pituitary or that are collaterals from them are responsible for its behavioural effects. ${ }^{23}$ It is believed so because the Oxytocin secreted from pituitary gland cannot re-enter brain as it cannot cross the blood-brain barrier.

\section{Functions related to reproduction}

Parturition and uterine contraction: Oxytocin causes contraction of uterine muscles and is commonly used to induce labour in clinical practice. Oxytocin acts on uterus already primed by oxytocin, at the time of parturition. Towards term, oxytocin secretion gradually increases and reaches its peak just before parturition. Also, number of oxytocin receptors increases in the uterine muscles. Due to increased plasma level of oxytocin and increased sensitivity of uterus to oxytocin, uterus contracts vigorously leading to expulsion of foetus. Thus oxytocin initiates and completes parturition. Parturition is a neuro-humoral reflex. ${ }^{24}$ During the first few weeks of lactation, Oxytocin that is released due to sucking by the infant leads to mild but often painful contractions. This later on serves to assist uterine involution. However Oxytocin is essential for milk ejection. ${ }^{25}$ 
Milk ejection: Discharge or expulsion of milk from the breast of mother into mouth of baby when baby suckles during breast feeding is called milk ejection reflex or milk let-down reflex. Action of Oxytocin at the mammary glands causes ejection of milk into the sub areolar sinuses, from where it is excreted. As the baby suckles at the nipple, an impulse is generated and is transmitted to the hypothalamus via spinal nerves. This nerve signal causes Oxytocin secretion from the neurosecretory magnocellular nerve terminals of the posterior pituitary. The direct effect of Oxytocin on the myoepithelial cells surrounding the milk cistern causes these cells to contract and propel milk towards outside. Oxytocin is also believed to cause an indirect effect on milking through the hormone, prolactin (PRL) ${ }^{26}$

Sexual behaviour: Studies show that, injection of Oxytocin into the cerebrospinal fluid causes spontaneous erections in rats ${ }^{9}$ and reflex actions in the hypothalamus and spinal cord. Oxytocin receptor antagonists that are administered centrally prevent non-contact erections. Oxytocin antagonists' administration to study the effect of Oxytocin on sexual behaviour in female rats showed that this hormone increased sexual responsiveness in them. ${ }^{27}$

Oxytocin receptors are found in the corpus cavernosum and epididymis of the penis in men. Therefore, binding of the hormone to these receptors in these areas may significantly have an impact on contractility ${ }^{28}$ and subsequent ejaculation. ${ }^{29}$ The amount of plasma oxytocin is found to increase during sexual arousal, and also orgasm can markedly raise the plasma levels of the hormone in men. ${ }^{30}$ Intranasal inhalation of oxytocin in men significantly increases plasma levels of oxytocin and epinephrine for minimum one hour, and also tend to increase self-perception of arousal during masturbation. ${ }^{31}$ As suggested in a recent case study, In addition, intranasal oxytocin administration during coitus may aid in treating anorgasmia in men in cases where medical conditions, drug abuse, and psychological issues have been excluded. ${ }^{32}$

The primary aim of oxytocin treatment in women is to induce labour, as it aids in the contraction of uterus. ${ }^{33}$ It is also known to ease breast-feeding, due to its milk-let down action. ${ }^{34}$ In a case study it was reported that the intranasal inhalation of oxytocin in order to facilitate breast-feeding increases lubrication of the vagina and arousal. ${ }^{35} \mathrm{Also}$ in women, oxytocin level elevates during sexual excitement and are further increased by orgasm..$^{36,37}$

Role in reproduction: Penile erection is essential for successful reproduction. Oxytocin is known to be one of the most potent inducer of erecting penis in man. ${ }^{26}$ Neurons within the paraventricular nucleus responsible for oxytocin secretion that project into extra hypothalamic areas, mainly spinal cord are involved in this action of the hormone. An Oxytocin based reflex arc similar to milk let down reflex in females, transmits somato-sensory signals from penis to hypothalamus. ${ }^{38}$ Oxytocin of hypothalamic origin is highly related with ejaculation. ${ }^{30,39}$ Certain postulates states that oxytocin has been found to modulate contractility of male reproductive tract in order to modulate sperm transportation and maturation ${ }^{26}$ and also the process of spermiation. ${ }^{40}$ The action of oxytocin on muscle contractibility may accelerate sperm and egg transport. Reports suggest an increase in plasma levels of oxytocin during orgasm in both the sexes30. Oxytocin may assist in regulation of testicular steroidogenesis. It also possesses an influence on conversion of testosterone into dihydrotestosterone. ${ }^{4}$

\section{Role in social functioning}

Oxytocin is involved in the regulation of a wide variety of intertwined behaviours. Oxytocin has a role in regulating the social behaviours of many species, and so can also influence the social behaviours in humans. Oxytocin helps in the emotional bonding between humans and dogs. Across species, Oxytocin is necessary in modulating the formation of social memories, and also expression of aggressive and affiliative behaviours. ${ }^{42}$

Social memory and social recognition: An aspect regarding social behaviour is social memory, the ability to recognize and differentiate between individuals. ${ }^{43}$ Recognition and the ability for differentiation between individuals is vital for everyday life. Without the ability to identify friend from foe, it is impossible to display the appropriate and suitable behaviours no matter whether it is affiliative or aggressive. Central oxytocin administration enhances social memory in male ${ }^{44,45}$ whereas an oxytocin receptor antagonist blocks social memory in female and male rats. ${ }^{44-46}$ Data from clinical studies reveal that oxytocin promotes face recognition in humans. Further investigation of social memory will provide more detailed analysis of the importance of Oxytocin in social memory. ${ }^{47}$

Affiliation and social bonding or parental behaviour: Older studies conducted in animals demonstrated oxytocin's capability to induce maternal behaviour ${ }^{48}$ and its significance in creating pairbonds, ${ }^{49}$ arranging the stages for investigations of oxytocin's role in social bonding and attachment. Markers of the oxytocinergic system have been found associated to parental behaviour and parent-infant relationship and bonding. For example, high levels of endogenous oxytocin during the postpartum period are linked with intensified mother-infant bonding. ${ }^{50}$ Along with these findings; it was also evident that, higher levels of oxytocin in plasma and saliva in mothers and fathers were positively correlated with the parents and child's social engagement, affect synchrony, and also positive communicative sequences between parent and child. ${ }^{51}$

Anxiety: Oxytocin can also function as an anxiolytic agent as it decreases stress hormone release in both humans ${ }^{52}$ and rats. ${ }^{53}$ Animal research has demonstrated relationships between oxytocin's role in anxiety and social behaviours. For example, under stress oxytocin causes rodents to maintain closeness with familiar rodents. ${ }^{54}$ Specifically, anxiety-provoking stimuli activate the oxytocin system by increasing oxytocin neuronal activity, oxytocin gene expression and peripheral release of oxytocin..$^{55}$ The acute and chronic anxiolytic effects of oxytocin have been demonstrated in a number of rodent study. Oxytocin in humans can work to reduce anxiety by increasing recognition and feelings of affiliation. ${ }^{56}$ Lower oxytocin levels of plasma reported in humans with depression..$^{57}$ Oxytocin released from brain also appears to reduce stress responses, including anxiety. These effects have been noticed in a variety of species. Oxytocin has the ability to evoke feelings of contentment, cause a reduction in anxiety, and feelings of calmness and security around the mate..$^{58}$

Love and trust: Different studies done previously have already revealed a correlation of Oxytocin with human bonding, and that it increases in trust and decreases in fear. The oxytocin amounts in blood rises during hugging and orgasm. People in their first stages of romantic attachment had increased levels of oxytocin, compared with those of non-attached single people. These levels remained stable for a minimum of 6 months. .It was firm that there was a positive correlation between plasma levels of oxytocin and romantic attachment between adults. Thus, this hormone is sometimes referred to as" love hormone". ${ }^{59}$ Oxytocin also enhances feelings of generosity, trust, and may help in the recognition and understanding of others' feelings. ${ }^{60}$ 


\section{Implications in human behaviour}

Autism: Autism spectrum disorder (ASD) is a type of brain disorder that onsets during early childhood. The characteristics of this disorder include core social communication impairments as well as restricted, repetitive behaviours, which threaten the formation of appropriate social skills and the conservation of social relationships. ${ }^{61,62}$ The positive correlation between oxytocin and formation of social bonds in animal studies has made many to believe that oxytocin abnormalities may play a role in autism. Actually, various studies indicate that single nucleotide polymorphisms (SNPs) in oxytocin is linked with ASD ${ }^{63}$ Infusion of oxytocin intravenously into adults with autism markedly reduces both number and severity of repetitive behaviours and also can enhance memory. Oxytocin therapy has the ability to reduce suffering in ASD patients by enhancing quality of life through improved social potentials. ${ }^{64}$ Administration of Oxytocin intranasally was found to increase emotion recognition ${ }^{65}$ and improvement of social behaviour. ${ }^{66}$

Schizophrenia: A disorder that affects a person's ability to think, feel and behave clearly is referred to as schizophrenia. People with schizophrenia may be like that they have lost their ideas with reality. It is one of the most disabling type of a psychiatric disorder, with a small proportion of patients troubled with this disorder possible to maintain independent function. ${ }^{67}$ Several early reports indicate that treatments with oxytocin induced sudden therapeutic results and was stayed away from hospitalization in patients with schizophrenia, ${ }^{68}$ where its potential action was by working as a "psychic energizer" thereby reversing energy, apathy, and depression. ${ }^{69}$ Oxytocin produced importantly greater therapeutic actions across a broad spectrum of symptoms that included both positive and negative symptom groups that were based upon changes in the Positive and Negative Syndrome Scale (PANSS). Clinical Global Impression (CGI) scores also were significantly found improved with oxytocin.

Eating behaviour: Several studies conducted in animals specifies that oxytocin is a powerful regulator of caloric intake and metabolism. A single dose of intranasally administered oxytocin seems to reduce male caloric intake, and these effects could become greater in them with the degree of obesity. Intranasal oxytocin acutely increases the burning of fat in order to use it up as a fuel for the bodily needs, but effects of the hormone in supplementing energy expenditure have not yet been manifested in man. In a pilot study conducted of 8 weeks duration, administration of intranasal oxytocin in a small group of men and women with overweight or obesity made to cause a considerable loss in their body weight. While emphasizing about the effects of the hormone irrespective of body weight, oxytocin might help to improve glucose homeostasis. Oxytocin also put forward some kind of novel therapeutic targets for both obesity and metabolic disorders. ${ }^{70}$

\section{Other implications}

In feeding and grooming: Oxytocin helps in the regulation of food and water intake. Generally, Oxytocin suppresses food intake. Oxytocin acts as a' satiety hormone'. Centrally-administered Oxytocin and Oxytocin agonists strongly inhibit feeding. ${ }^{71}$ Oxytocin antagonists prevent this inhibition..$^{72,73}$ Oxytocin inhibits water intake in freely-drinking animals which I dependent on the dosage, also it can induce thirst. ${ }^{73}$ During pregnancy period, hyper-phagia occurs as a consequence of decreased activity of magnocellular oxytocin neurons that tend to inhibit its release. ${ }^{74}$

Oxytocin magnifies grooming activity in both the sexes of rats.
Other studies confirm the relationship and elucidate that selected regions of the brain can control grooming behaviour. ${ }^{75}$ Infusion of oxytocin initiates self grooming. ${ }^{9}$

Cellular proliferation and cancer: The knowledge about the connection between oxytocin and cancer is scarce, partly because of the lack of appropriate research in this area or due to the inconsistency in the current data. Oxytocin modulate mitotic activity in various organs. The role of oxytocin in cellular proliferation is found to be tissue specific. Oxytocin can act as a factor in differentiation of cells, and it is now identified that the neuro-hormone can also serve as a growth factor, which can control cell proliferation, with an eminent effect on cancer cells. At the same time, oxytocin hinders the proliferation of neoplastic cells of the epithelium in mammary glands and endometrium, nerves and bone, both exogenously ${ }^{76-79}$ and endogenously. ${ }^{80}$ The hormone also promotes cell multiplication in the trophoblast and endothelium..$^{81,82}$ Various signalling pathways are indulged in these reverse actions.

The connection of oxytocin's role to vasopressin and its potential action as a biomarker was successively proposed in the year $1990 .{ }^{83}$ It was recommended that oxytocin may serve in modulating the intensity of growth in breast cancer. ${ }^{84}$ Also as its role in the mitigation of prostate function was already established, its potential part in prostate cancer development has also been proposed. Oxytocin can serve as a prostate cancer biomarker. ${ }^{85}$

Studies show that oxytocin restrain proliferation of breast cancer cell lines, ${ }^{86,87}$ Oxytocin was also found to prevent the progression of ovarian carcinoma both in vitro and in vivo. ${ }^{88}$ Some evidences precisely implicate oxytocin's role in carcinogenesis, although its explicit effect and underlying processes are still not clear.

Pain perception: Pain is a normal sensation set off in the nervous system as a warning signal to the possibility of injury and also the need for rest and recuperation. Animal studies reviewed that there is relation between oxytocin and pain perception. Oxytocin causes analgesia for acute or chronic pain in humans. Oxytocin lowers pain threshold in rats. Oxytocin has been recognized recently as a significant mediator of endogenous analgesia ${ }^{89,90}$ and it can reduce frequency of headache and pain in chronic migraine.${ }^{91}$ It has also been reported that oxytocin decreases thoracic cancer pain. ${ }^{92}$ Decreased concentrations of oxytocin seems to be markedly associated with pain, stress, and depression in fibromyalgia patients. ${ }^{93}$ In case of low plasma levels of oxytocin it was found that there was a reduced pain tolerance for noxious cold and ischemic stimuli. ${ }^{94}$ Recent research indicates that oxytocin along with acupuncture can specifically increase the pain threshold. It was also proposed that this association was an active process underlying acupuncture-induced analgesia. ${ }^{95,96}$

Well-being: Oxytocin causes a feeling of well-being such as calm, improved social interactions, trust, decreased fear, human bonding as well as hormonal and physiological changes. ${ }^{97-99}$ Oxytocin has the ability to induce the feelings of contentment, bring about the decrease in anxiety and causes a feeling of security and also calmness in the mate..$^{58}$ Oxytocin is also associated with stress linked behaviour, learning and even memory. ${ }^{98}$ The effects of oxytocin causes blood pressure reduction, calm and affiliative behaviour. Oxytocin is of potential use in well-being and applications in neuropsychiatric disorders. ${ }^{99}$ Additional studies reveals that patients with major depression holds markedly reduced levels of plasma oxytocin; ${ }^{100}$ low levels of oxytocin in plasma have been correlated with depressive symptoms. ${ }^{57}$ Oxytocin has been proven to serve as a potent antidepressant. ${ }^{101}$ 


\section{Conclusion}

Oxytocin is a hormone with variety of functions including reproduction, social functioning, implications in human behaviour etc .A brief description of each functions are covered in this article. Further studies are required to find out the role of oxytocin in cancer and eating behaviours.

\section{Acknowledgments}

None.

\section{Conflicts of interest}

The author declares no conflict of interest.

\section{References}

1. Du Vigneaud V, Ressler C, Swan JM, et al. The synthesis of an octapeptide amide with the hormonal activity of Oxytocin. $J$ Am Chem Soc. 1953;75(19):4879-4880.

2. Robinson AG. The neurohypophysis: recent developments. J Lab Clin Med. 1987;109(3):336-345.

3. Zimmerman EA, Robinson AG, Husain MK, et al. Neurohypophysial peptides in the bovine hypothalamus: the relationship of Neurophysin I to Oxytocin, and Neurophysin II to vasopressin in supraoptic and paraventricular regions. Endocrinology. 1974;95(4):931-936.

4. Land H, Grez M, Ruppert $\mathrm{S}$, et al. Deduced amino acid sequence from the bovine Oxytocin-Neurophysin I precursor cDNA. Nature. 1983;302(5906):342-344.

5. Renaud LP, Bourque CW. Neurophysiology and neuropharmacology of hypothalamic magnocellular neurons secreting vasopressin and Oxytocin. Prog Neurobiol. 1991;36(2):131-136.

6. Sheldric EL, Flint AP. Post-translational processing of Oxytocin-neurophysinprohormone in the ovine corpus luteum: activity of peptidylglycine alpha-amidating mono-oxygenase and concentrations of its cofactor, ascorbic acid. Journal of Endocrinology. 1989;122(1):313-322.

7. Nicholson HD, Swann RW, Burford GD, et al. Identification of Oxytocin and vasopressin in the testis and in adrenal tissue. Regul Pept. 1984;8(2):141-146.

8. Wathes DC, Swann RW, Bricket SD, et al. Characterization of Oxytocin vasopressin and neurophysin from bovine corpus luteum. Endocrinology. 1983;113(2):693-698.

9. Gimpl G, Fahrenholz F. The Oxytocin receptor system: structure, function, and regulation. Physiol Rev. 2001;81(2):629-683.

10. Filippi S, Luconi M, Granchi S, et al. Estrogens, but not androgens, regulate expression and functional activity of Oxytocin receptor in rabbit epididymis. Endocrinology. 2002a;143(11):4271-4280.

11. Assinder SJ, Carey M, Parkinson T, et al. Oxytocin and vasopressin expression in the ovine testis and epididymis: changes with the onset of spermatogenesis. Biol Reprod. 2000;63(2):448-456.

12. Guldenaar SE, Pickering BT. Immunochemical evidence of presence of Oxytocin in rat testis. Cell Tissue Research. 1985;240(2):485-487.

13. Whittington K, Assinder S, Gould M, et al. Oxytocin, oxytocin associated neurophysin and the oxytocin receptor in human prostate. Cell Tissue Res. 2004;318(2):375-382.

14. Ang VT, Jenkins JS. Neurohypophysial hormones in adrenal medulla. $J$ Clin Endocrinol Metab. 1984;58(4):688-691.

15. Fields PA, Eldridge RK, Fuchs AR, et al. Human placental and bovine corpora luteal Oxytocin. Endocrinology. 1983;112(4):1544-1546.
16. Gauquelin G, Geelen G, Louis F, et al. Presence of vasopressin, Oxytocin and neurophysin in the retina of mammals, effect of light and darkness, comparison with neuropeptide content of neurohypophysis and the pineal gland. Peptides. 1983;4(4):509-515.

17. Geenen V, Legros JJ, Franchimont P, et al. The neuroendocrine thymus: coexistence of Oxytocin and neurophysin in human thymus. Science. 1986;232(4749):508-511.

18. Amico JA, Finn FM, Haldar J. Oxytocin and vasopressin are present in human and rat pancreas. Am J Med Sci. 1988;296(5):303-307.

19. Caldwell HK, Lee HJ, Macbeth AH, et al. Vasopressin: behavioural roles of an "original" Neuropeptide. Prog Neurobiol. 2008;84(1):1-24.

20. Young WS 3rd, Gainer H. Transgenesis and the study of expression, cellular targeting and function of oxytocin, vasopressin and their receptors. Neuroendocrinology. 2003;78(4):185-203.

21. Sanborn BM, Dodge K, Monga M, et al. Molecular mechanisms regulating the effects of oxytcin on myometrial intracellular calcium. $A d v$ Exp Med Biol. 1998;449:277-286.

22. Fuchs AR, Husslein P, Fuchs F. Oxytocin and the initiation of human parturition. II. Stimulation of prostaglandin production in human decidua by Oxytocin. Am J Obstet Gynecol. 1981;141(6):694-697.

23. Ross HE, Cole CD, Smith Y, et al. Characterization of Oxytocin system regulating affiliative behavior in female prairie voles. Neuroscience. 2009;162(4):892-903.

24. Mitchell BF, Fang X, Wong S. Oxytocin: a paracrine hormone in the regulation of parturition. Rev Reprod. 1998;3(2):113-122.

25. Nishimore K, Young LJ, Guo Q, et al. Oxytocin is required for nursing but is not essential for parturition or reproductive behaviour. Proc Natl Acad Sci USA. 1996;93(21):11699-11704.

26. Thackare H, Nicholson HD, Whittington K. Oxytocin-its role in male reproduction and new potential therapeutic uses. Human Reproduction Update. 2006;12(4):437-448.

27. Arletti R, Bartolini A. Oxytocin stimulates lordosis behaviour in female rats. Neuropeptides. 1985;6(3):247-253.

28. Vignozzi L, Filippi S, Luconi M, et al. Oxytocin receptor is expressed in the penis and mediates an estrogen-dependent smooth muscle contractility. Endocrinology. 2004;145(4):1823-1834.

29. Filippi S, Vignozzi L, Vannelli GB, et al. Role of oxytocin in the ejaculatory process. $J$ Endocrinol Invest. 2003;26:82-86.

30. Carmichael MS, Humbert R, Dixen J, et al. Plasma oxytocin increases in the human sexual response. J Clin Endocrinol Metab. 1987;64(1):27-31.

31. Burri A, Heinrichs M, Schedlowski M, et al. The acute effects of intranasal oxytocin administration on endocrine and sexual function in males. Psycho neuro endocrinology. 2008;33(5):591-600.

32. Ishak WW, Berman DS, Peters A. Male anorgasmia treated with oxytocin J Sex Med. 2008;5(4):1022-1024.

33. Carter CS. Developmental consequences of oxytocin. Physiol Behav. 2003;79(3):383-397.

34. Anderson PO, Valdes V. A critical review of pharmaceutical galactagogues. Breastfeed Med. 2007;2(4):229-242.

35. Anderson-Hunt M, Dennerstein L. Increased female sexual response after oxytocin. BMJ. 1994;309(6959):929.

36. Blaicher W, Gruber D, Bieglmayer C, et al. The role of oxytocin in Relation to female sexual arousal. Gynecol Obstet Invest. 1999;47(2):125-126.

37. Carmichael MS, Humbert R, Dixen J, et al. Plasma oxytocin increases in the human sexual response. J Clin Endocrinol Metab.1987;64(1):27-31. 
38. Yanagimoto M, Honda $\mathrm{K}$, Goto $\mathrm{Y}$, et al. Afferents originating from the dorsal penile nerve excite Oxytocin cells in the hypothalamic paraventricular nucleus of the rat. Brain Res. 1996;733(2):292-296.

39. Murphy MR, Seckl JR, Burton S, et al. Changes in Oxytocin and vasopressin secretion during sexual activity in men. $J$ Clin Endocrinol Metab. 1987;65(4):738-741.

40. Harris GC, Nicholson HD. Stage-related differences in rat seminiferous tubule contractility in vitro and their response to Oxytocin. J Endocrinol. 1998a;157(2):251-257.

41. Nicholson HD, Guldenaar SE, Boer GJ, et al. Testicular Oxytocin: effects of intratesticular Oxytocin in the rat. J Endocrinol. 1991;130(2):231-238.

42. Neumann ID, Landgraf R. Advances in vasopressin and oxytocin--from genes to behaviour to disease. Preface. Prog Brain Res. 2008;170:xixiii.

43. Lukas M, Neumann ID. Oxytocin and vasopressin in rodent behaviour related to social dysfunctions in autism spectrum disorders. Behav Brain Res. 2013;251:85-94.

44. Benelli A, Bertolini A, Poggioli R, et al. Polymodal dose-response curve for oxytocin in the social recognition test. Neuropeptides. 1995;28(4):251-255.

45. Engelmann M, Ebner K, Wotjak CT, et al. Endogenous oxytocinis involved in short-term olfactory memory in female rats. Behav Brain Res.1998;90(1):89-94.

46. Lukas M, Toth I, Veenema AH, et al. Oxytocin mediates rodentsocial memory within the lateral septum and the medial amygdaladepending on the relevance of the social stimulus: male juvenile versus female adult conspecifics. Psychoneuroendocrinology. 2013;38(6):916-926.

47. Lee HJ, Caldwell HK, Macbeth AH, et al. A conditional knockout mouse line of the oxytocin receptor. Endocrinology. 2008;149(7):3256-3263.

48. Pedersen CA, Prange Jr AJ. Induction of maternal behavior in virgin rats after intracerebroventricular administration of oxytocin. Proc Natl Acad Sci USA. 1979;76(12):6661-6665.

49. Insel TR. A neurobiological basis of social attachment. Am J Psychiatry. 1997;154(6):726-735.

50. Feldman R, Weller A, Zagoory-Sharon O, et al. Evidence for a neuroendocrinological foundation of human affiliation: plasma oxytocin levels across pregnancy and the postpartum period predict mother-infant bonding. Psychol Sci. 2007;18(11):965-970.

51. Feldman R, Gordon I, Zagoory-Sharon O. Maternal and paternal plasma, salivary, and urinary oxytocin and parent-infant synchrony: considering stress and affiliation components of human bonding. Dev Sci. 2011;14(4):752-761.

52. Legros JJ. Inhibitory effect of oxytocin on corticotrope function in humans: are vasopressin and oxytocin ying-yang neurohormones? Psychoneuroendocrinology. 2001;26(7):649-655.

53. Stachowiak A, Macchi C, Nussdorfer GG, et al. Effects of oxytocin on the function and morphology of the rat adrenal cortex: in vitr $o$ and in vivo investigations. Res Exp Med (Berl). 1995;195(5):265-274.

54. Engelmann M, Wotjak CT, Neumann I, et al. Behavioral consequences of intracerebral vasopressin and oxytocin: focus onlearning and memory. Neurosci Biobehav Rev. 1996;20(3):341-358.

55. Gibbs DM. Dissociation of oxytocin, vasopressin, and corticotropin secretion during different types of stress. Life Sci. 1984;35(5):487-491.

56. Kosfeld M, Heinrichs M, Zak PJ, et al. Oxytocin increases trust in humans. Nature. 2005;435(7042):673-676.

57. Scantamburlo G, Hansenne M, Fuchs S, et al. Plasma oxytocin levels and anxiety in patients with major depression. Psychoneuroendocrinology. 2007;32(4):407-410
58. Meyer-Dixie. Selective serotonin reuptake inhibitors and their effects on relationship satisfaction. The family journal. 2007;15(4):392-397.

59. Marazziti D1, Dell'Osso B, Baroni S, et al. A relationship between Oxytocin and anxiety of romantic attachment. Clin Pract Epidemiol Ment Health. 2006;2:8

60. Lee HJ, Macbeth AH, Pagani J, et al. Oxytocin: the Great Facilitator of Life. Prog Neurobiol. 2009;88(2):127-151.

61. American Psychiatric Association. Diagnostic and Statistical Manual of Mental Disorders: Diagnostic Criteria for Autistic Disorder. 5th ed. Washington, DC: Am Psychiatr Assoc; 2013.

62. Hammock EA, Young LJ. Oxytocin, vasopressin and pair bonding: implications for autism. Philos Trans $R$ Soc Lond B Biol Sci. 2006;361(1476):2187-2198.

63. Yrigollen CM, Han SS, Kochetkova A, et al. Genes controlling affiliative behavior as candidate genes for autism. Biol Psychiatry. 2008;63(10):911916.

64. Hollander E, Bartz J, Chaplin W, et al. Oxytocin increases retention of social cognition in autism. Biol Psychiatry. 2007;61(4):498-503.

65. Guastella AJ, Einfeld EL, Gray K, et al. Intranasal Oxytocin improves emotion recognition of youth with autism spectrum disorders. Biol psychiatry. 2010;67(7):692-694.

66. Andaria E, Duhamela JR, Zallab T, et al. Promoting social behaviour with Oxytocin in high functioning autism spectrum disorders. Proc Natl Acad Sci USA. 2010;107(9):4389-4894.

67. van Os J, Kenis G, Rutten BP. The environment and schizophrenia. Nature. 2010;468(7321):203-212.

68. Bujanow W. Hormones in the treatment of psychoses. $\mathrm{Br}$ Med $\mathrm{J}$. 1972;4(5835):298.

69. Bakharev VD, Tikhomirov SM, Lozhkina TK. Psychotropic properties of oxytocin. Neurosci BehavPhysiol. 1986;16(2):160-164.

70. Elizabeth A Lawson. The effects of oxytocin on eating behaviour and metabolism in human. Nat Rev Endocrinol. 2017;13(12):700-709.

71. Olson BR, Drutarosky MD, Chow MS, et al. Oxytocin and an oxytocin agonist administered centrally decrease food intake in rats. Peptides. 1991;12(1):113-118.

72. Arletti R, Benelli A, Bertolini A. Influence of oxytocin on feeding behavior in the rat. Peptides. 1989;10(1):89-93.

73. Arletti R, Benelli A, Bertolini A. Oxytocin inhibits food and fluid intake in rats. Physiol Behav. 1990;48(6):825-830.

74. Douglas AJ, Johnstone LE, Leng G. Neuroendocrine mechanisms of change in food intake during pregnancy: a potential role for brain oxytocin. Physiol Behav. 2007;91(4):352-365.

75. Drago F, Caldwell JD, Pedersen CA, et al. Dopamine neurotransmission in the nucleus accumbens may be involved in oxytocin-enhanced grooming behavior of the rat. Pharmacol Biochem Behav. 1986a;24(5):1185-1188.

76. Cassoni P, Sapino A, Negro F, et al. Oxytocin inhibits proliferation of human breast cancer cell lines. Virchows Arch. 1994;425(5):467-472.

77. Cassoni P, Sapino A, Stella A, et al. Presence and significance of oxytocin receptors in human neuroblastomas and glial tumors. Int $J$ Cancer. 1998;77(5):695-700.

78. Cassoni P, Fulcheri E, Carcangiu M, et al. Oxytocin receptors in human adenocarcinomas of the endometrium: Presence and biological significance. J Pathol. 2000;190(4):470-477.

79. Novak J, Judkins M, Chernin M, et al. A plasmin-derived hexapeptide from the carboxyl end of osteocalcin counteracts oxytocin-mediated growth inhibition [corrected] of osteosarcoma cells. Cancer Res. 2000;60(13):3470-3476. 
80. Cassoni P, Sapino A, Papotti M, et al. Oxytocin and oxytocin-analogue F314 inhibit cell proliferation and tumor growth of rat and mouse mammary carcinomas. Int J Cancer. 1996;66(6):817-820.

81. Cassoni P, Sapino A, Munaron L, et al. Activation of functional oxytocin receptors stimulates cell proliferation in human trophoblast and choriocarcinoma cell lines. Endocrinology. 2001;142(3):1130-1136.

82. Cassoni P, Sapino A, Deaglio S, et al. Oxytocin is a growth factor for Kaposi's sarcoma cells: Evidence of endocrine-immunological cross-talk. Cancer Res. 2002;62(8):2406-2413.

83. Legros JJ, Geenen V, Carvelli T, et al. Neurophysins as markers of vasopressin and oxytocin release. A study in carcinoma of the lung. Horm Res. 1990;34(3-4):151-155.

84. Taylor AH, Ang VT, Jenkins JS, et al. Interaction of vasopressin and oxytocin with human breast carcinoma cells. Cancer Res. 1990;50(24):7882-7886.

85. Xu H, Fu S, Chen Q, et al. The function of oxytocin: a potential biomarker for prostate cancer diagnosis and promoter of prostate cancer. Oncotarget. 2017;8(19):31215-31226.

86. Cassoni P, Sapino A, Marrocco T, et al. Oxytocin and oxytocin receptors in cancer cells and proliferation. J Neuroendocrinol. 2004;16(4):362-364.

87. Cassoni P, Catalano MG, Sapino A, et al. Oxytocin modulates estrogen receptor alpha expression and function in MCF7 human breast cancer cells. Int J Oncol. 2002;21(2):375-378.

88. Morita T, Shibata K, Kikkawa F, et al. Oxytocin inhibits the progression of human ovarian carcinoma cells in vitro and in vivo. Int $J$ Cancer. 2004;109(4):525-532.

89. Juif JE, Poisbeau P. Neurohumoral effects of oxytocin and vasopressin receptor agonists on spinal pain processing in male rats. Pain 2013;154(8):1449-1456.

90. Murphy D, Konopacka A, Hindmarch C. The hypothalamicneurophypohyseal system: from genome to physiology.JNeuroendocrinol. 2012;24(4):539-553.
91. Wang YL, Yuan Y, Yang J, et al. The interaction between the oxytocin and pain modulation in headache patients. Neuropeptides. 2013;47(2):93-97.

92. Madrazo I, Franco-Bourland R, Leon-Meza V, et al. Intraventricular somatostatin-14, arginine vasopressin, and oxytocin: analgesic effect in a patient with intractable cancer pain. Appl Neurophysiol. 1987;50(16):427-431.

93. Grewen KM, Light $\mathrm{KC}$, Mechlin B, et al. Ethnicity is associated with alterations inoxytocin relationships to pain sensitivity in women. Ethn Health. 2008;13(3):219-241.

94. Yang J. Intrathecal administration of oxytocin induces analgesia in low back pain involving the endogenous opiate peptide system. Spine (Phila Pa 1976). 1994;19(8):867-871.

95. Yang J, Yang Y, Chen JM, et al. Effect of hypothalamic supraoptic nucleus on acupuncture analgesia in the rat. Brain Res Bull. 2008;75(5):681-686.

96. Yang J, Yang Y, Chen JM, et al. Effect of oxytocin on acupuncture analgesia in the rat. Neuropeptides. 2007;41(5):285-292.

97. Shamay-Tsoory SG1, Fischer M, Dvash J, et al. Intranasal administration of Oxytocin increases envy and schadenfreude (gloating). Biol psychiatry. 2009;66(9):864-870.

98. Assad NI, Pandey AK, Sharma LM. Oxytocin, functions, uses and abuses: a brief review. Theriogenology Insight. 2016;6(1):1-17.

99. Ishak WW, Kahloon M, Fakhry H. Oxytocin role in enhancing wellbeing: a literature review. J Affect Disord. 2011;130(1-2):1-9.

100. Frasch A, Zetzsche T, Steiger A, et al. Reduction of plasma oxytocin levels in patients suffering from major depression. Adv Exp Med Biol. 1995;395:257-258.

101. Arletti R, Bertolini A. Oxytocin as an antidepressant in two animal models of depression. Life Sci. 1987;41(14):1725-1730. 